\title{
Degradation of o-xylene by a novel strain, Zoogloearesiniphila HJ1: Identification, kinetics and metabolic pathway
}

\author{
Jianming $\mathrm{Yu}^{1}{ }^{1}$, , Qian Liu ${ }^{1}$, Jun Hu${ }^{2}$ and Zhuohuan Feng ${ }^{1}$ \\ ${ }^{1}$ Collaborative Innovation Center of Green Pharmaceutical Engineering, Zhejiang University of Technology, Hangzhou, China \\ ${ }^{2}$ Key Laboratory of Drinking Water Science and Technology, Research Center for Eco-Environmental Sciences, University of Chinese \\ Academy of Sciences, Chinese Academy of Sciences, Beijing, China
}

Received: 31/07/2016, Accepted: 11/10/2016, Available online: 29/09/2017

*to whom all correspondence should be addressed:

e-mail: yjm@zjut.edu.cn

\begin{abstract}
Biodegradation has become a popular alternative remediation technology due to its economical and ecological advantages. A strain able to degrade $o$-xylene effectively was selected and identified as Zoogloearesiniphila HJ1. The organism, strain HJ1, could degrade $o$-xylene with concentration as high as $256 \mathrm{mg} \mathrm{L}^{-1}$ at $\mathrm{pH} 6.8$ and $26.3{ }^{\circ} \mathrm{C}$. The Haldane model adequately described the relationship between specific growth rate and substrate concentration. The maximum specific growth rate and yield coefficient were $0.118 \mathrm{~h}^{-1}$ and 0.2572 , respectively. A high mineralization rate of $67.9 \%$ was observed. Theenzyme activity and metabolic intermediates analysis showed that the ring cleavage of $o$ xylene was catalyzed by catechol 1,2-dioxygenase, and 3,4dimethylcatechol was the main metabolic product. The present study demonstrated that the isolated strain, Zoogloearesiniphila $\mathrm{HJ}$, had a great application prospect for remediation of $o$-xylene-contaminated environment.
\end{abstract}

Keywords: O-xylene; Zoogloearesiniphila; Biodegradation; Kinetics; Metabolic pathway

\section{Introduction}

O-xyleneis a polluting agent derived from petroleum-like refining fuel, such as coating, colorant and solvent, and commonly found in polluted environmental media around the petrochemical industries and synthetic chemicals (Morlett-Chávez et al., 2010). Much attention has been drawn to how to remove $o$-xyleneas which is toxic and more soluble in water than the rest of hydrocarbons. $O$ xylene is harmful to human health and can cause fatigue, confusion, headache, dizziness, and even death (Mazzeo and Marin-Morales, 2011). The U.S. Environmental Protection Agency has defined $o$-xylene as a priority pollutant and established the maximum permissible concentration level to be $10 \mathrm{ppm}$ (Guo et al., 2013). Therefore, its elimination from the environment becomes an important issue.

Biodegradation appears to be an effective and eco-friendly technology for remediation of contaminated sites under aerobic, microaerobic and anaerobic conditions (Martino et al., 2012; W. Sun et al., 2009; Zhang et al., 2012). In recent years, biodegradation of typical organic compounds (such as benzene, toluene) to $\mathrm{CO}_{2}, \mathrm{H}_{2} \mathrm{O}$ and biomass by specialized bacteria has received great attention (Chakraborty et al., 2006; Hildebrand and Mackenzie, 2008; Lu et al., 2015; Ryu et al., 2008). Since o-xylene, one type of the three isomers of xylene, has the lowest biodegradability, its biodegradation and metabolizing pathways have been rarely reported. Recent studies showed that some effective degraders were isolated and biodegradation of 0 -xylene by aerobic and anaerobic bacteria could be achieved, including Pandoraea sp strain WL1, Cladophialopharo sp., Rhodococcus sp. strain DK1, Pseudomonas putida F1 etc (D Kim et al., 2004; Dockyu Kim et al., 2010; Prenafetaboldú et al., 2002; Wang et al., 2015). Although these microorganisms can feasibly degrade o-xylene, their slow growth rates and 
biodegradation rates under natural conditions have limited their use in bioremediation. Several methods (such as optimization of growth conditions, seeking of co-metabolic compounds, detection of key metabolites) have been tried to enhance biodegradation process, and make degraders show higher biodegradation activity compared to their original state (Shadi et al., 2013; Yang et al., 2008; Yao et al., 2009). In addition, microorganism was cultured in optimal conditions as their introduction into bioreactors could accelerate biofilm formation and improve operational stability (Baptista et al., 2008; Emanuelsson et al., 2005). Accurate determination of biodegradation kinetics is required to design cost effective and reliable bioreactors for treatment of contaminated groundwater and industrial effluents (Feisther et al., 2015). Therefore, isolation and characterization of target bacterial strains will be most important to bioremediation of typical recalcitrant compounds.

In the present study, a new identified bacterium that could degrade $o$-xylene was first isolated from the active sludge of a pharmaceutical factory. The isolator was identified as Zoogloearesiniphila and its degradation ability for o-xylene was not reported in previous studies. Investigation of growth conditions and kinetics was carried out for determination of degradation characteristics. Kinetic parameters of $p$-xylene degradation were determined and fitted to the Haldane equation (Feisther et al., 2015). Then, based on measurement of special enzyme activity and detection of intermediates during degradation, a novel metabolic pathway for $o$-xylene was proposed. Such results provided fundamental data and theoretical guidance for further application of the isolator in the $o$-xylene bioremediation system.

\section{Materials and methods}

\subsection{Experiment Materials}

1) Active Sludge

Active sludge was collected from a SBR aeration tank of a pharmaceutical Factory in Xinchang, Zhejiang Province.

\section{2) Culture Medium}

The mineral medium for acclimation and isolation contained the following mineral salt $\left(\mathrm{mg} \mathrm{L}^{-1}\right)$ : $\mathrm{KH}_{2} \mathrm{PO}_{4} 1000$, $\mathrm{Na}_{2} \mathrm{HPO}_{4} 4500, \quad\left(\mathrm{NH}_{4}\right)_{2} \mathrm{SO}_{4} 500, \mathrm{MgSO}_{4} 100, \mathrm{CaCl}_{2} 20$, $\mathrm{MnSO}_{4} \cdot 4 \mathrm{H}_{2} \mathrm{O} \quad 100, \mathrm{ZnSO}_{4} \cdot 7 \mathrm{H}_{2} \mathrm{O} 100, \mathrm{CuSO}_{4} \cdot 5 \mathrm{H}_{2} \mathrm{O} 20$, $\mathrm{CoCl}_{2} \cdot 6 \mathrm{H}_{2} \mathrm{O} 2 \mathrm{O}, \mathrm{Na}_{2} \mathrm{MoO}_{4} \cdot 2 \mathrm{H}_{2} \mathrm{O} 20, \mathrm{FeSO}_{4} \cdot 7 \mathrm{H}_{2} \mathrm{O} 1, \mathrm{H}_{3} \mathrm{BO}_{3} 0.02$, $\mathrm{pH7.3} 7.55$. The solution was autoclaved at $110^{\circ} \mathrm{C}$ for 40 min, under which the medium could not turn turbid. $O$ xylene was added as carbon and energy source.

\subsection{Strain purification and identification}

Preliminary characterizations were based on morphological and physiological land biochemical tests. Further identification was completed by $16 \mathrm{~S}$ rRNA gene sequencing according to the method described (Guo et al., 2013). Phylogenetic trees were generated from alignments by the neighbor-joining method. The reliability of inferred trees was tested via the bootstrap test with the MEGA4 program. The strain HJ1 (Genbank No. JQ751310, CCTCC NO. M2012235) was currently deposited in China Center for Type Cultural Collection (Wuhan).

\subsection{Degradation and mineralization of o-xylene by the} isolator

Experiments were carried out at $35^{\circ} \mathrm{C}$ on an orbital shaker at $160 \mathrm{rpm}$ in the dark. Cells grown on MSM with o-xylene were harvested by centrifugation (16000g, $15 \mathrm{~min}$ ), and the cell pellet was re-suspended in a fresh MSM. Aliquots of this suspension were placed into the serum bottles, and $o$ xylene was added as the carbon source. Incubation was performed in the dark on a rotary shaker (150 rpm). Growth was monitored by gas phase measurement of 0 xylene and biomass density compared with o-xylene consumption and cell production in non-inoculated controls.

The final mineralization product $\mathrm{CO}_{2}$ was measured by a gas chromatography. When $\mathrm{CO}_{2}$ concentration in the sealed serum bottle reached its maximum value, and was not varied with the time, $1 \mathrm{~mL} 30 \% \mathrm{HCl}$ was added into the bottle to transform liquid phase $\mathrm{HCO}_{3}{ }^{-}$completely into $\mathrm{CO}_{2}$, which was released into gas phase. $\mathrm{CO}_{2}$ concentration was determined again after $0.5 \mathrm{~h}$.

For research on the dynamics of single substrate degradation and cell yield, Haldane equation was employed to describe the process of degrading substrate at different initial concentrations, with equations represented as follows:

$$
\mu_{i}=\frac{1}{X} \frac{d X}{d t}=\frac{\mu_{\max _{i}} S_{i}}{K_{S_{i}}+S_{i}+S_{i}^{2} / K_{I}} v_{i}=\frac{1}{X} \frac{d S_{i}}{d t}=\frac{v_{\text {max }_{i}} S_{i}}{K_{S_{i}}+S_{i}+S_{i}^{2} / K_{I}}
$$

In the equations, $X$ : concentration of stains, $\mathrm{mg} / \mathrm{L}$; $\mathrm{t}$ : time, $\mathrm{h}$; $\mathrm{S}$ : concentration of the substrate, $\mathrm{mg} / \mathrm{L} ; \mu_{\max }$ : maximum specific growth rate, $\mathrm{h}^{-1}$, Ks: half saturation coefficient, 
$\mathrm{mg} / \mathrm{L}$; $\mathrm{K}_{\mathrm{I}}$ : inhibition coefficient, $\mathrm{mg} / \mathrm{L}$; $\mathrm{V}_{\max }$ : maximum specific degradation rate

\subsection{Analytical techniques}

\subsubsection{Morphological observation}

The observation was processed on Nikon general photon microscope and JEOL JEM-1230-TEM.

\section{1) $16 \mathrm{~S}$ rRNA identification}

DNA was extracted using a TaKaRa MiniBEST Universal Genomic DNA Extraction Kit Ver. 4.0 (Takara Code: D824A). The bacterial universal primers BSF8/20(5'-AGAGT TTGAT CCTGG CTCAG-3) and BSR1541/20 (5'-AAGGA GGTGA TCCAG CCGCA-3') (TaKaRa Biotechnology, Dalian, China) were used for amplification, which was performed in a thermalcycle (PTC 200, Bio-Rad, USA) according to the method described by Zhang et al(Li et al., 2011). Sequencing was measured by TaKaRa Biotechnology Co.,Ltd (Dalian, China) and all the 16S rRNA gene sequences were checked manually for phylogenetic analysis.

\section{2) $\mathrm{CO}_{2}$ analysis}

Concentrations of $o$-xylene and $\mathrm{CO}_{2}$ were measured by $\mathrm{GC}$ analysis of headspace. Headspace concentrations were converted to aqueous-phase concentrations using Henry's law constants. All samples, irrespective of incubation temperature of the cultures, were equilibrated at $25^{\circ} \mathrm{C}$ before GC analysis. An $800-\mu \mathrm{L}$ headspace sample was injected into $\mathrm{GC}$ for $\mathrm{o}$-xylene and $\mathrm{CO}_{2}$ analysis.

\section{3) O-xyleneanalysis}

$O$-xylene concentration was detected by a $6890 \mathrm{~N}$ GC (Agilent Technologies, America), with a HP-Innowax capillary column $(30 \mathrm{~m} \times 0.32 \mathrm{~mm} \times 0.5 \mu \mathrm{m})$ and a FID detector. The injector and detector temperatures were set at $180{ }^{\circ} \mathrm{C}$ and $200{ }^{\circ} \mathrm{C}$, respectively. The oven temperature was programmed as follows: initial $90^{\circ} \mathrm{C}$ maintained for 4 min, increased to $150^{\circ} \mathrm{C}$ at $30^{\circ} \mathrm{C} \mathrm{min}^{-1}$ and maintained for 0.5 min. For $\mathrm{CO}_{2}$ measurement, a HP-Plot-Q column (30 $\mathrm{m} \times 0.32 \mathrm{~mm} \times 20 \mu \mathrm{m})$ and a TCD detector were used. The injector, oven and detector temperature were $90^{\circ} \mathrm{C}, 40^{\circ} \mathrm{C}$ and $100{ }^{\circ} \mathrm{C}$, respectively.

\section{4) Metabolites analysis}

Metabolites at different sampling intervals were extracted from the culture by equal volume of ethyl acetate, dried over by anhydrous sodium sulphate and evaporated to dryness under high-purity $\mathrm{N}_{2}$ stream. GC/MS (Agilent
7890N/MS 5975) equipped with a HP-5MS capillary column (30 $\mathrm{m} \times 0.25 \mathrm{~mm} \times 0.25 \mu \mathrm{m}$ ) was used for analyzing these metabolites. Conditions for GC/MS were as follows: oven temperature $100^{\circ} \mathrm{C}$ for $1 \mathrm{~min}$, ramped to $280^{\circ} \mathrm{C}$ at $5^{\circ} \mathrm{C} \mathrm{min}^{-}$ ${ }^{1}$ and held for $10 \mathrm{~min}$. Injector temperature was $180^{\circ} \mathrm{C}$. The MS interface temperature was set at $280^{\circ} \mathrm{C}$ and the ionization source at $250^{\circ} \mathrm{C}$. The mass spectra were obtained at $70 \mathrm{eV}$. All metabolites were identified by GC/MS through matching retention times and ion spectra with authentic standard and NIST library data.

5) Determination of enzyme activity

The activity of catechol 1,2-dioxygenase and catechol 2,3dioxygenase was determined by the formations of cis, cismuconate, 2-hydroxymuconic semialdehyde, and the characteristic absorbance was respectively 260 and $375 \mathrm{~nm}$ measured by a spectrophotometer (UV2910, Shimadzu,Japan) (Cao et al., 2008). Enzyme reaction was conducted in $4 \mathrm{~mL}$ deionized water, which contained 33 $\mu \mathrm{mol}$ Tris- $\mathrm{HCl}, 1.3 \mu \mathrm{mol} \mathrm{Na}_{2}$ EDTA, $0.5 \mu \mathrm{mol}$ catechol and $100 \mu \mathrm{L}$ enzyme. Enzyme activity was calculated as follows: $\mathrm{U} / \mathrm{mg}=\Delta \mathrm{A} \times \mathrm{V} /(\varepsilon \times \mathrm{M})$

Where, $\Delta \mathrm{A}$ is the change of absorbance per minute at the wavelength of $260 \mathrm{~nm}$ and $375 \mathrm{~nm}$; $V$ is the total reaction volume detected by enzyme activity, $L ; \varepsilon$ is the molar extinction coefficient of catechol at $260 \mathrm{~nm}$ and $365 \mathrm{~nm}$, $(\mathrm{mmol} \cdot \mathrm{cm})^{-1} ; \mathrm{M}$ is protein content, $\mathrm{mg}$.

\section{Results and discussion}

\subsection{Identification of the isolated strain}

1) Morphological observation

By strain screening and rescreening, an isolator (coded as HJ1) with high $o$-xylene degradation ability was selected. Results of Gram staining showed that the strain was gramnegative with a flagellum (Fig. 1a) and its oxidase was positive. The colonial morphology of strain HJ1 was circular, the edge of which is neat, moist and smooth. The shape of strain HJ1 was short rod, with the mean size of (0.8 1.0) $\mu \mathrm{m} \times\left(1.2^{\sim 1.5)} \mu \mathrm{m}\right.$ (Fig. 1b).

\section{2) $16 \mathrm{~S}$ rRNA sequence analysis}

The 16S rRNA of strain HJ1 (Genbank No. JQ751310 CCTCC NO. M2012235) was sequenced to determine its phylogenetic position as depicted in Fig. 1c. Since 16S rRNA sequence of strain HJ1 shows $99 \%$ similarity to that of Zoogloearesiniphila strain DhA-35 (NR027188). 


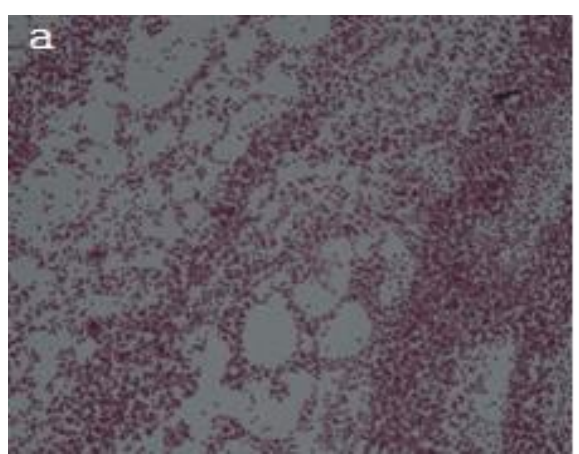

(a)

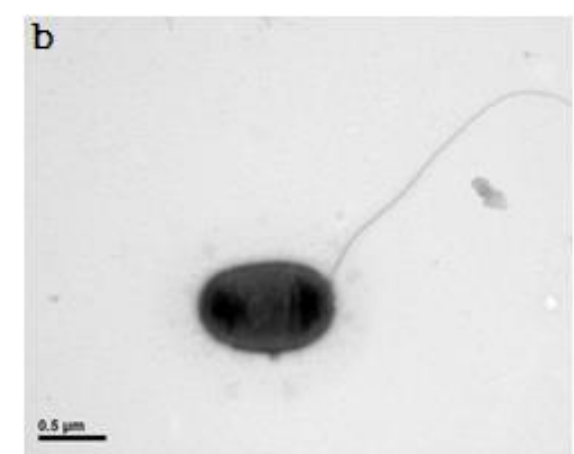

(b)

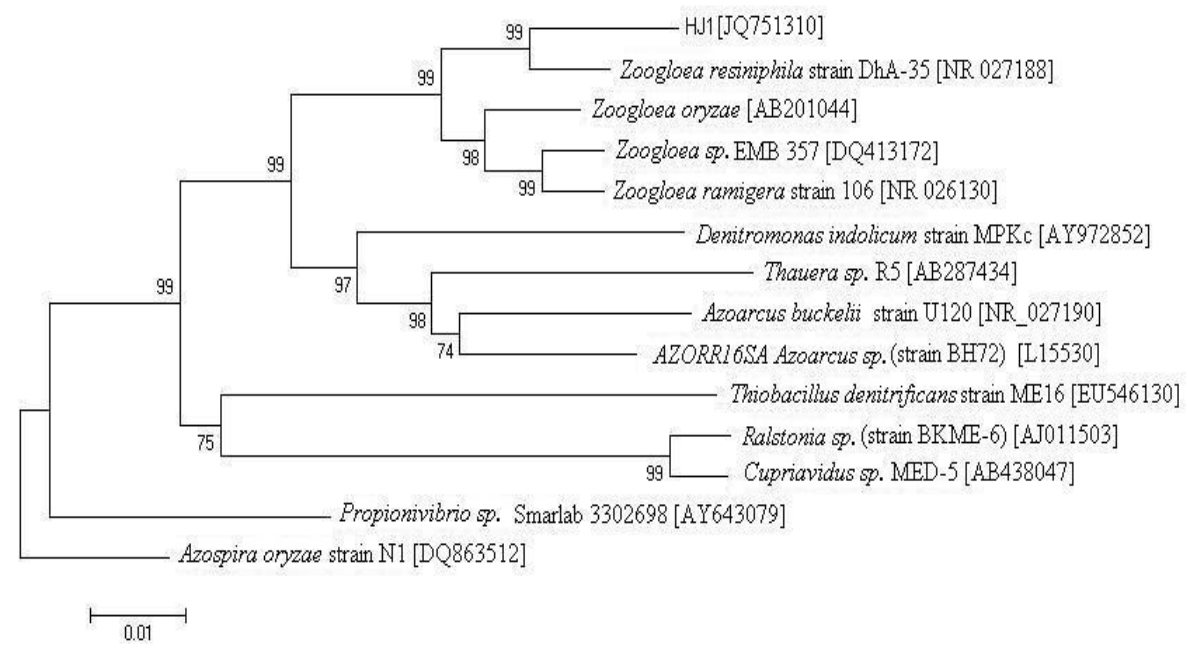

(c)

Figure 1. Morphological observation and 16S rRNA sequence analysis: (a) Gram stain; (b) TEM image; (c) Phylogenetic tree of the strain with other closely related strain

\subsection{Degradation characteristics of o-xylene by strain HJ1}

1) Effect of $\mathrm{pH}$ and temperature

Initial $\mathrm{pH}$ and growth temperature were two important factors that affected bacteria growth and degradation activity for special compounds (Sharma et al., 2009). Fig.2 shows the growth and degradation characteristics with initial $o$-xylene of $128 \mathrm{mg} \mathrm{L}^{-1}$ under different $\mathrm{pH}$ values and temperatures. Incubated for $24 \mathrm{~h}$, removal efficiency of $o$ xylene arrived at its maximum value $99.9 \%$ (biomass being $43.7 \mathrm{mg} \mathrm{L}^{-1}$ ) under $\mathrm{pH}$ of 7. As for growth temperature, strain $\mathrm{HJ} 1$ could grow very well at $35^{\circ} \mathrm{C}$, and removal efficiency was $99.8 \%$ (biomass being $44.2 \mathrm{mg} \mathrm{L}^{-1}$ ). Song indicated that $\mathrm{pH}$ and temperature of o-xylene degradation was 7.5 and $27{ }^{\circ} \mathrm{C}$ in soil, respectively (Song, 2003), with temperature slightly lower than the strain HJ1. Biodegradation rate for 0 -xylene was nearly $20 \%$ faster than that obtained under non-optimized cultural conditions ( $\mathrm{pH} 7$ and temperature $\left.30^{\circ} \mathrm{C}\right)$.

2) Effect of initial $o$-xylene concentration

The ability of strain $\mathrm{HJ} 1$ to degrade $o$-xylene was evaluated by monitoring degradation efficiency of $o$-xylene at different initial concentrations ranging from $30-300 \mathrm{mg} \mathrm{L}^{-1}$ under optimal conditions. Fig. 3 shows o-xylene concentration and cell concentration profiles with respect to incubation time. As shown in Fig. 3, a complete reduction was achieved at about $10 \mathrm{~h}$ with an initial concentration of $32 \mathrm{mg} \mathrm{L}^{-1}$ or at about $105 \mathrm{~h}$ with an initial concentration of $256 \mathrm{mg} \mathrm{L}^{-1}$. When $\mathrm{o}$-xylene concentration was increased to $288 \mathrm{mg} \mathrm{L}^{-1}$, strain $\mathrm{HJ} 1$ failed to completely degrade $o$-xylene and $40.5 \%$ remained in the cultural medium, suggesting that $o$-xylene concentrations in excess of $288 \mathrm{mg} \mathrm{L}^{-1}$ would inhibit the growth of strain $\mathrm{HJ} 1$ strongly. The growth yield of strain HJ1 was linear up to an 
approximately $o$-xylene concentration of $160 \mathrm{mg} \mathrm{L}^{-1}$ and no direct relationship was found between these parameters when concentration reached $192 \mathrm{mg} \mathrm{L}^{-1}$ and above. Such a phenomenon was caused by the toxicity of higherconcentration $o$-xylene and the corresponding energydependent adaptive response of the strain.
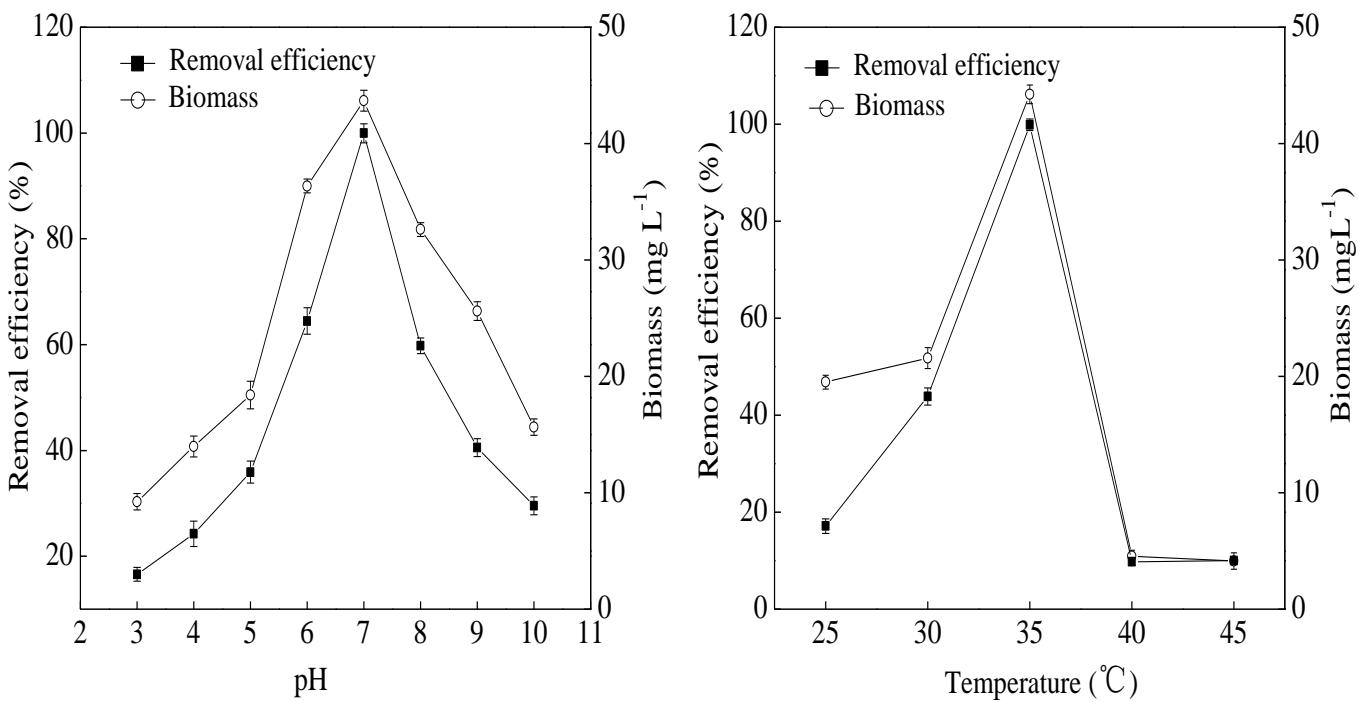

Figure 2. Effect of $\mathrm{pH}$ and temperature on $o$-xylene degradation by strain $\mathrm{HJ} 1$.
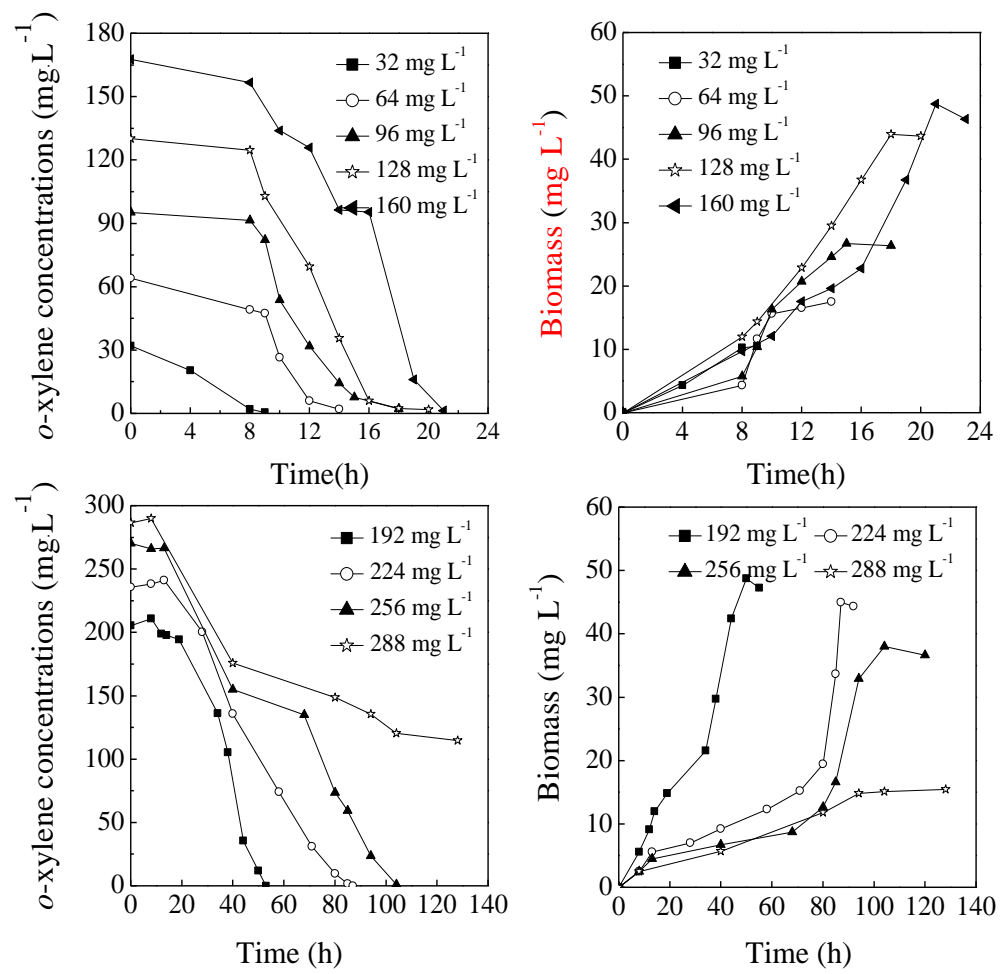

Figure 3. Different amounts of $o$-xylene as an increasing substrate by strain HJ1 under optimal conditions

In previous studies, a few species were reported to have the ability for biodegradation of $o$-xylene. Even some researchers indicated that $o$-xylene could only be completely degraded in the presence of other aromatic compounds (such as benzene, toluene), and $o$-xylene was not utilized as the sole carbon or energy source (RobledoOrtíz et al., 2011; Zhang et al., 2012). Compared to strains described elsewhere, this isolate HJ1 was able to degrade $o$-xylene individually and could degrade rather higher concentrations of $o$-xylene than the reported ones. Strain 
HJ1 tolerated o-xylene in $256 \mathrm{mg} \mathrm{L}^{-1}$ and completely degraded it in $105 \mathrm{~h}$, while strain P. Putida F1 was previously reported to degrade $30 \mathrm{mg} \mathrm{L}^{-1}$ o-xylene with removal efficiency of $80 \%$ (Robledo-Ortíz et al., 2011). From a practical perspective, this isolate is important for further application in bioremediation as it is relatively resistant to elevated $o$-xylene concentrations and refuses to utilize $o$-xylene as the sole carbon source without any other sources.

\subsection{Kinetics and biotic losses}

Batch experiments were conducted to evaluate the kinetics of $o$-xylene utilization and calculate the growth yield. Growth kinetics was determined using the Haldane model (Datta et al., 2014; Feisther et al., 2015).The mathematical programme of Origin 8.0 was used for analyzing the Haldane equations. The plot between specific growth rate and $o$-xylene concentration was shown in Fig.4a. The specific growth increased with $o$-xylene concentration and reached its maximum at approximately $96 \mathrm{mg} \mathrm{L}^{-1}$.
Concentrations above this level affected the specific growth rate negatively as substrate inhibition became stronger. Then, the correlation coefficient was tested at the initial concentration of $96 \mathrm{mg} \mathrm{L}^{-1}$. Kinetic parameters of oxylene degradation were fitted to the Haldane equations (Feisther et al., 2015) and correlation coefficient $\left(R^{2}\right)$ was 0.9978. Kinetic parameters that fitted to the model were: $0.118 \mathrm{~h}^{-1}$ for $\mu_{\max }, 18.46 \mathrm{mg} \mathrm{L}^{-1}$ for $\mathrm{K}_{\mathrm{s}}$, and $169.75 \mathrm{mg} \mathrm{L}^{-1}$ for $\mathrm{K}_{\mathrm{I}}$. A microbial consortium was isolated for biodegradation of $o$-xylene and its specific growth rate of $\mu_{\max }=0.14 \mathrm{~h}^{-1}$ was obtained from the Haldane model (Goudar and Strevett, 1998), slightly higher than that of strain HJ1. Fig.4b shows that the plot was used to determine the biomass yield coefficient of strain HJ1 on 0 -xylene. The value of yield coefficient was 0.2572 . As illustrated before, initial concentrations higher than $192 \mathrm{mg} \mathrm{L}^{-1}$ would inhibit the growth of strain HJ1, so biomass amount could not fit the line very well. With the increase of initial concentration, the deviation phenomenon was more evident.

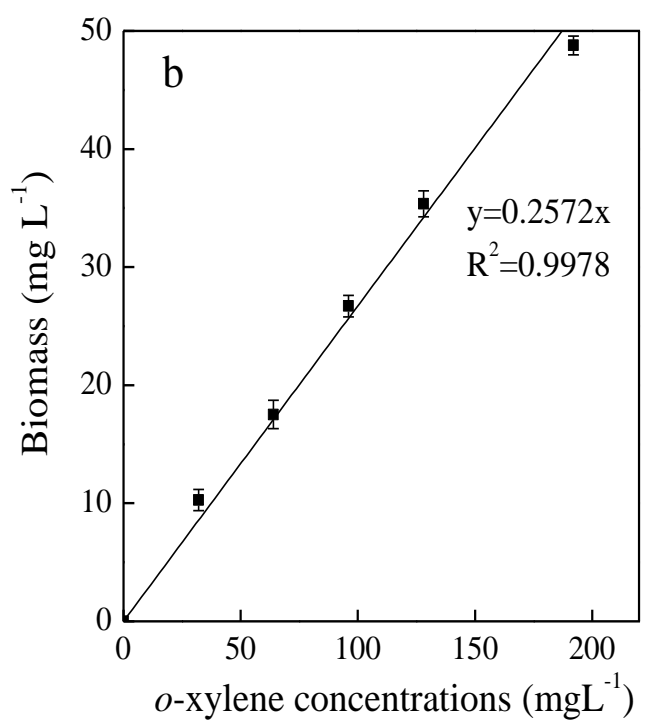

Figure 4. Relationship between o-xylene concentration and microbial growth rate: (a) Haldane's growth model fitted to the results of batch growth experimental data; (b) plot to calculate the yield coefficient for strain HJ1 growth on $o$-xylene

To investigate baiotic losses and sorption in strain $\mathrm{HJ} 1$ growth on 0 -xylene, initial concentration was set at $96 \mathrm{mg}$ $\mathrm{L}^{-1}$. The control group was compared to the experiment group lacking strain HJ1 (Tab.1). After 18 h, o-xylene concentration of the control group and the experiment group was 95.42 and $6.58 \mathrm{mg} / \mathrm{L}$, respectively. It was shown that baiotic losses and sorption had little effect on $o$-xylene concentration. In addition, biomass of the experiment group increased to $26.36 \mathrm{mg} / \mathrm{L}$. Strain HJ1 growth was determined as the main factor for reduction of $o$-xylene concentration.

\subsection{Mineralization of o-xylene by strain HJ1}

In the biodegradation process, organic pollutants were used as essential carbon source for microbial growth and aerobically degraded to $\mathrm{H}_{2} \mathrm{O}$ and $\mathrm{CO}_{2}$ (Ralebitsosenior et al., 2012). Therefore, $\mathrm{CO}_{2}$ production was an important parameter to evaluate the degradability of organic 
compounds, which provides further valuable information on the complete removal. $\mathrm{CO}_{2}$ production as a function of o-xylene consumed at different concentrations was presented in Fig. 5, indicating a linear relationship.

Table 1. Biotic losses and sorption of $o$-xylene

\begin{tabular}{ccccc}
\hline & & & \multicolumn{3}{c}{ Experiment group $(\mathrm{mg} / \mathrm{L}$} \\
& & & & \\
\cline { 2 - 5 } & Concentration & Biomass & Concentration & Biomass \\
\hline $0 \mathrm{~h}$ & 96 & 0 & 96 & 0 \\
\hline 18 & 95.42 & 0 & 6.58 & 26.36 \\
$\mathrm{~h}$ & & & & \\
\hline
\end{tabular}

The mean experimental data below $192 \mathrm{mg} \cdot \mathrm{L}^{-1}$ were found to lie reasonably around $y=1.821 x$, showing that $1 \mathrm{mg} o$ xylene could be completely mineralized to produce 1.821 $\mathrm{mg} \mathrm{CO}$. In theory, the stoichiometric ratio should be 3.32 in the case of complete oxidation of $o$-xylene to $\mathrm{H}_{2} \mathrm{O}$ and $\mathrm{CO}_{2}$. Therefore, carbon mineralization of $o$-xylene by strain HJ1 was around 54.8\%.

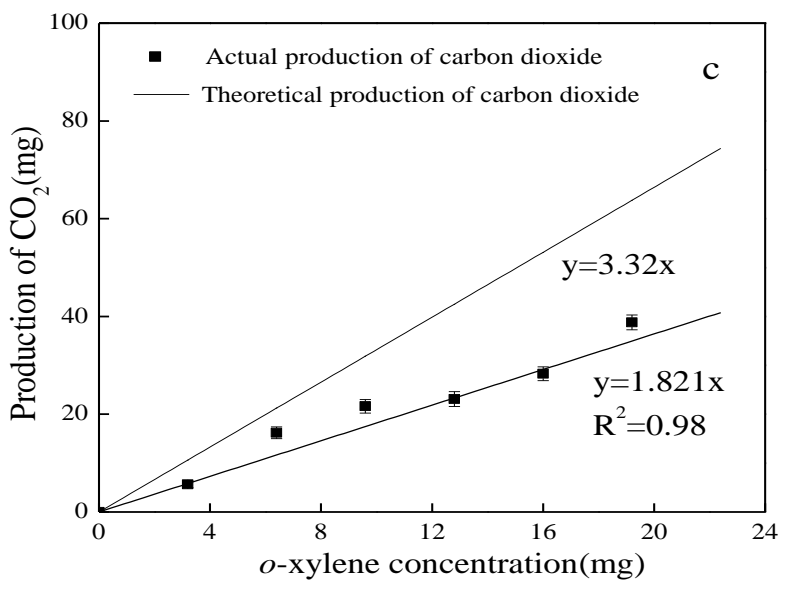

Figure 5. $\mathrm{CO}_{2}$ productions of $o$-xylene with different initial concentrations

The strain Mycobacterium cosmeticumbyf-4 utilized oxylene as the sole carbon source and the mineralization rate was approximately $65.5 \%$ (Zhang et al., 2012). Compared with other aromatic compounds, such low mineralization rates suggested that $o$-xylene was relatively difficult for complete mineralization into compounds by microorganisms.

The discrepancy between the theoretical ratio (3.32) and the experimental ratio (1.82) indicated that $\mathrm{CO}_{2}$ was not the only final conversion of carbon by strain $\mathrm{HJ} 1$, and remaining between them might be other conversions accumulated during biodegradation, such as biomass and extracellular polymers (Delhoménie et al., 2002).Through metabolic effects of strain HJ1, $0.9057 \mathrm{mg} C$ contained by 1 $\mathrm{mg} o$-xylene could be converted to $0.4966 \mathrm{mg} \mathrm{C}-\mathrm{CO}_{2}$ and $0.1187 \mathrm{mg}$ C-biomass, from which a carbon recovery efficiency of $67.93 \%$ was calculated .

3.5. Possible metabolic intermediates of o-xylene and its pathway

Resting cells were inoculated in the sterilized phosphate buffer ( $\mathrm{pH}$ 7.2) solution for determination of metabolic intermediates. The initial substrate concentrations were 50 and $200 \mathrm{mg} \mathrm{L}^{-1}$, and each was continuously detected for 64 or $200 \mathrm{~h}$. The identities of main metabolic intermediates were confirmed by GC-MS. Through identification by comparison with commercially available authentic standards and by matching against a mass spectra library,

3, 4-dimethylcatechol was detected as a main intermediate, (Fig. 6 shows its gas chromatogram and mass spectrum). Kim et al. indicated that there were several different pathways of $o$-xylene by different microorganisms. It has been proposed that identified intermediates were 3,4-dimethylcatechol or 4,5dimethylcatechol from the successive monooxidations of the aromatic ring to form 2,3-dimethylphenol or 3,4dimethylphenol. Therefore, detection of 3, 4dimethylcatechol showed that strain $\mathrm{HJ}$ might contain monooxidation enzyme that could oxidize the aromatic ring.

After formation of dihydroxylated compounds, there were two manners of ring cleavage, ortho (between the two hydroxylated carbons) or meta (between a hydroxylated and non-hydroxylated carbon) (Bozinovski et al., 2014; Prabhu and Phale, 2003; J. Q. Sun et al., 2009; Zeinali et al., 2008).Since the ring-cleavage intermediates, which processed polar groups, were hardly detected by GC/MS, dioxygenase activity was applied to indirectly testify the manner of ring cleavage.

Catechol 1,2-dioxygenase and catechol 2,3-dioxygense activity assays were performed by measurement of absorbance at 260 or $375 \mathrm{~nm}$, since these wavelengths were special forcis, cis-muconic acid or 2-hydroxymuconic semialdehyde(2-HMSA), respectively(Cao et al., 2008). Catechol-1,2-dioxygenase activity to hydroquinone and catechol was conducted on cells grown on different carbon sources, including $o$-xylene. The highest activity was observed with $\mathrm{YE}+O$-xylene or only $o$-xylene as assay substrates; the activity was induced with LB, glucose and YE 
as substrates which were reduced gradually, but at significant levels. However, catechol-2,3-dioxygense activity was not detected in any cell extracts. It suggested that hydroquinone and catechol were further oxidized to the ring cleavage products by the action of relative nonspecific 1,2-dioxygenase enzymes (Tab. 2), i.e., further breakdown of these compounds by HJ1 proceeded via the ortho-cleavage. It was also indicated that the relative enzyme was an induced enzyme, which had the activity in the presence of $o$-xylene.

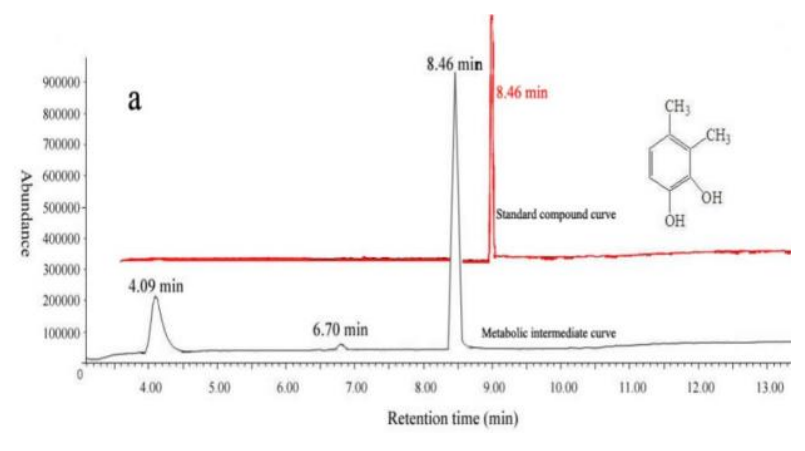

(a)

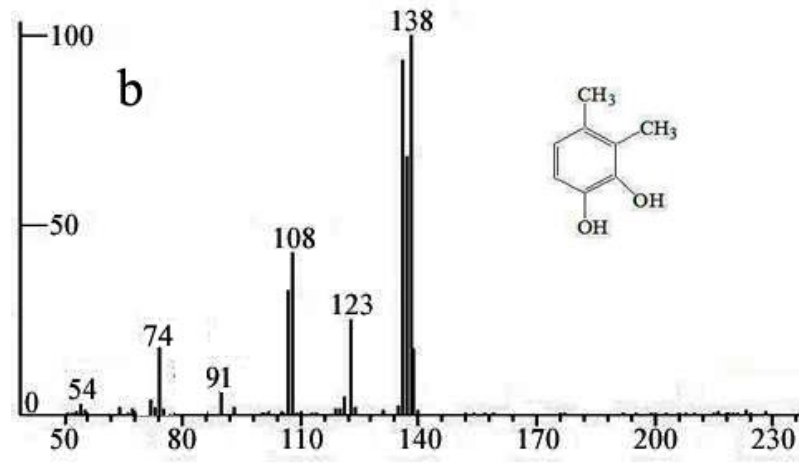

(b)

Figure 6. (a) GC/MS chromatogram of $o$-xylene biodegradation intermediates by strain $\mathrm{HJ} 1$; (b) the mass spectrums of the mainintermediates

Table 2. Activity and inducibility of enzymes involved in o-xylene degradation pathway in strain HJ1.

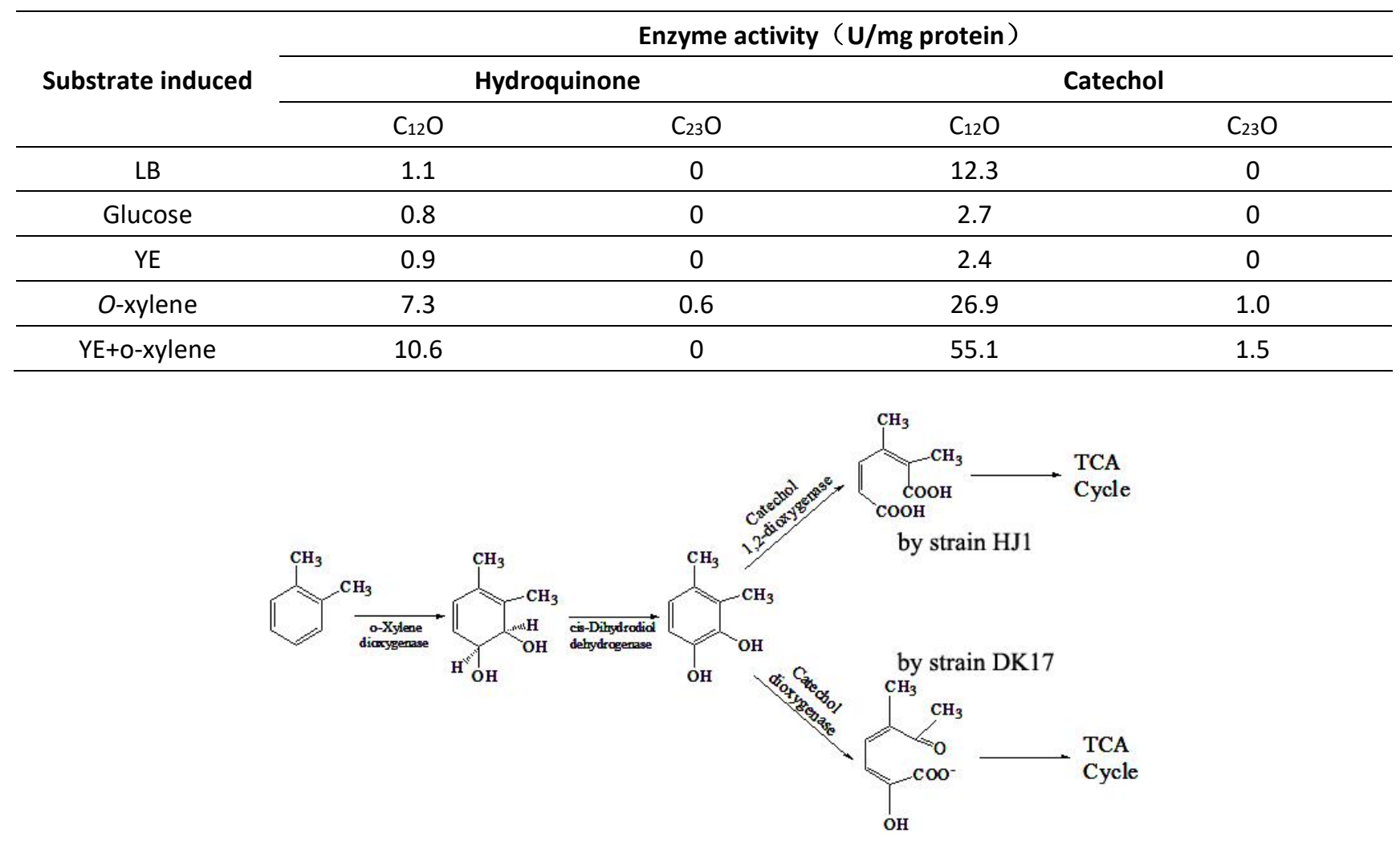

Figure 7. Possible metabolic pathways of o-xylene by Zoogloearesiniphila stain HJ1 and Rhodococcus sp. strain DK17

Based on these results, a different possible pathway was proposed as shown in Fig.7 for initial attack on o-xylene. Before the ring cleavage, the pathway was similar to the one reported by Kim et al. (D Kim et al., 2004; Dockyu Kim et al., 2010), in which Rhodococcus sp. strain DK17 was utilized for degradation of 0 -xylene. $O$-xylene was firstly converted to 1,2-dihydroxy-3,4-dimethyl-cyclohexane-3,5diene, which was then transformed into 3,4- 
dimethylcatechol (detected in the study) under the function of dioxygenase and cis-dihydrodiol dehydrogenase, respectively. But for the ring cleavage, the manner processed by strain HJ was different from others. 3,4-dimethylcatechol was converted to ring-opening products in the manner of ortho, and then such ringopening products entered the cycle of TCA to generate the completely mineralized products $\left(\mathrm{CO}_{2}, \mathrm{H}_{2} \mathrm{O}\right.$ etc. $)$ and biomasses.

\section{Conclusions}

The Zoogloea species HJ1 (Genbank No JQ751310) capable of effectively degrading $o$-xylene was isolated and identified in the present study. The optimum values of $\mathrm{pH}$ and temperature were 6.8 and $26.3^{\circ} \mathrm{C}$. Under optimal conditions, $256 \mathrm{mg} \mathrm{L}^{-1} \mathrm{o}$-xylene could be completely degraded. Specific growth rate complied with the Haldane kinetic equation; the maximum value was $0.118 \mathrm{~h}^{-1}$ when $o_{-}$ xylene concentration reached $20 \mathrm{mg} \mathrm{L}^{-1}$. With $o$-xylene concentration higher than $288 \mathrm{mg} \mathrm{L}^{-1}$, the strain growth and degradation was significantly inhibited. The cell yield coefficient of $0.2572 \mathrm{mg}$ (mgo-xylene) ${ }^{-1}$ by the isolated strain and $\mathrm{CO}_{2}$ production rate of up to $54.8 \%$ proved that removal of substrate was mainly via mineralization and incorporation into cell material. New pathways for $o$-xylene degradation were proposed by identification of metabolites and assay of ring cleavage enzymes in cell extracts. Results showed that 3,4-dimethylcatechol was an important intermediate and the manner of ring cleavage was ortho. The isolated strain $\mathrm{HJ}$ would have a potential application for bioremediation of $o$-xylene pollution, and the enzyme possessed by strain $\mathrm{HJ}$ would have engineering application value for purification of aromatic compounds.

\section{Acknowledgments}

This study was sponsored by NSFC (21576241) and the Key Basic Research of the Ministry of Science and Technology of China (No. 2014CB460608). We also thank anonymous reviewers for helpful comments on the manuscript.

\section{References}

Baptista I.I.R., Zhou, N.Y.†, Emanuelsson E.A.C., Peeva, L. G., Leak D. J., Mantalaris A. and Livingston A. G. (2008), Evidence of species succession during chlorobenzene biodegradation, Biotechnology \& Bioengineering, 99(1), 68-74.

Bozinovski D., Taubert M., Kleinsteuber S., Richnow H.H., Bergen M.V., Vogt C. and Seifert J. (2014), Metaproteogenomic analysis of a sulfate-reducing enrichment culture reveals genomic organization of key enzymes in the $m$-xylene degradation pathway and metabolic activity of proteobacteria, Systematic and Applied Microbiology, 37(7), 488-501.

Cao B., Geng A. and Loh K.C. (2008), Induction of ortho - and meta -cleavage pathways in Pseudomonas in biodegradation of high benzoate concentration: MS identification of catabolic enzymes, Applied Microbiology \& Biotechnology, 81(1), 99107.

Chakraborty R., O'Connor S.M., Chan E. and Coates J.D. (2006), Anaerobic degradation of benzene, toluene, ethylbenzene, and xylene compounds by Dechloromonas strain RCB, Applied \& Environmental Microbiology, 71(12), 8649-8655.

Datta A., Philip L. and Bhallamudi S.M. (2014), Modeling the biodegradation kinetics of aromatic and aliphatic volatile pollutant mixture in liquid phase, Chemical Engineering Journal, 241(2), 288-300.

Delhoménie M.C., Bibeau L. and Heitz M. (2002), A study of the impact of particle size and adsorption phenomena in a compost-based biological filter, Chemical Engineering Science, 57(24), 4999-5010.

Emanuelsson E.A.C., Baptista I.I.R., Mantalaris A. and Livingston A.G. (2005), Strain stability in biological systems treating recalcitrant organic compounds. Biotechnology \& Bioengineering, 92(7), 843-849.

Feisther V.A., Souza A.A.U.D., Trigueros D.E.G., Mello J.M.M.D. and Oliveira D.D. (2015). Biodegradation kinetics of benzene, toluene and xylene compounds: microbial growth and evaluation of models, Bioprocess \& Biosystems Engineering, 38(7), 1233-1241.

Goudar C.T. and Strevett K.A. (1998), Comparison of relative rates of BTEX biodegradation using respirometry, Journal of Industrial Microbiology \& Biotechnology, 21(1-2), 11-18.

Guo H., Yao J., Chen H., Wang J., Masakorala K., Jin Y. and Blake R.E. (2013), Substrate interactions during biodegradation of benzene/alkylbenzene mixtures by Rhodococcus sp. USTB-1, International Biodeterioration \& Biodegradation, 75(3), 124130.

Hildebrand H. and Mackenzie K. (2008), Novel nano-catalysts for wastewater treatment, Global Nest Journal, 10(1), 47-53.

Kim D., Chae J.C., Zylstra G.J., Kim Y.S., Kim S.K., Nam M.H. and Kim E. (2004), Identification of a novel dioxygenase involved in metabolism of o-xylene, toluene, and ethylbenzene by Rhodococcus sp. strain DK17, Applied \& Environmental Microbiology, 70(12), 7086-7092.

Kim D., Lee C.H., Choi J.N., Choi K.Y., Zylstra G.J. and Kim E. (2010), Aromatic Hydroxylation of Indan by o-Xylene-Degrading 
Rhodococcus sp. Strain DK17, Applied \& Environmental Microbiology, 76(1), 375-377.

Li L.Z., Shou Q.L., Zhu R.Y. and Jian M.C. (2011), Degradation of chlorobenzene by strain Ralstonia pickettii L2 isolated from a biotrickling filter treating a chlorobenzene-contaminated gas stream, Applied Microbiology \& Biotechnology, 91(2), 407415.

Lu Q., Toledo R.A.D., Xie F., Li J. and Shim H. (2015), Combined removal of a BTEX, TCE, and cis-DCE mixture using Pseudomonas sp. immobilized on scrap tyres, Environmental Science \& Pollution Research, 22(18), 14043-14049.

Martino C.D., López N.I. and Lustman L.J.R. (2012), Isolation and characterization of benzene, toluene and xylene degrading Pseudomonas sp. selected as candidates for bioremediation, International Biodeterioration \& Biodegradation, 67(2), 1520.

Mazzeo D.E.C. and Marin-Morales M.A. (2011), Cellular damages in the Allium cepa test system, caused by BTEX mixture prior and after biodegradation process, Chemosphere, 85(1), 13-18.

Morlett-Chávez J.A., Ascacio-Martínez J.Á., Rivas-Estilla A.M., Velázquez-Vadillo J.F., Haskins W.E., Barrera-Saldaña H.A. and Acuña-Askar K. (2010), Kinetics of BTEX biodegradation by a microbial consortium acclimatized to unleaded gasoline and bacterial strains isolated from it, International Biodeterioration \& Biodegradation, 64(7), 581-587.

Prabhu Y. and Phale P.S. (2003), Biodegradation of phenanthrene by Pseudomonas sp. strain PP2: novel metabolic pathway, role of biosurfactant and cell surface hydrophobicity in hydrocarbon assimilation, Applied Microbiology \& Biotechnology, 61(4), 342-351.

Prenafetaboldú F.X., Vervoort J., Grotenhuis J.T. and Van Groenestijn J.W. (2002), Substrate interactions during the biodegradation of benzene, toluene, ethylbenzene, and xylene (BTEX) hydrocarbons by the fungus Cladophialophora sp. strain T1, Applied \& Environmental Microbiology, 68(6), 2660-2665.

Ralebitsosenior T.K., Senior E., Felice R.D. and Jarvis K. (2012), Waste Gas Biofiltration: Advances and Limitations of Current Approaches in Microbiology, Environmental Science \& Technology, 46(16), 8542-8573.

Robledo-Ortíz J.R., Ramírez-Arreola D.E., Pérez-Fonseca A.A., Gómez C., González-Reynoso O., Ramos-Quirarte J. and González-Núñez R. (2011), Benzene, toluene, and o-xylene degradation by free and immobilized P. putida F1 of postconsumer agave-fiber/polymer foamed composites, International Biodeterioration \& Biodegradation, 65(3), 539546.
Ryu H.W., Kim S.J., Cho K.S. and Lee T.H. (2008), Toluene degradation in a polyurethane biofilter at high loading, Biotechnology \& Bioprocess Engineering, 13(3), 360-365.

Shadi A.M., Yaghmaei S., Vafaei F., Khataee A.R. and Hejazi M.S. (2013), Degradation of benzene, toluene, and xylene (BTX) from aqueous solution by isolated bacteria from contaminated sites, Research on Chemical Intermediates, 41(1), 265-275.

Sharma P., Singh L. and Dilbaghi N. (2009), Response surface methodological approach for the decolorization of simulated dye effluent using Aspergillus fumigatus fresenius, Journal of Hazardous Materials, 161(2-3), 1081-1086.

Sun J.Q., Xing H., Chen Q.L., Liang B., Qiu J.G., Ali S.W. and Li S.P. (2009), Isolation and characterization of three Sphingobium sp. strains capable of degrading isoproturon and cloning of the catechol 1,2-dioxygenase gene from these strains, World Journal of Microbiology \& Biotechnology, 25(2), 259-268.

Sun W., Xie S., Luo C. and Cupples A.M. (2009), Direct link between toluene degradation in contaminated-site microcosms and a Polaromonas strain, Applied \& Environmental Microbiology, 76(3), 956-959.

Song H.G. (2003), Degradation of humus-bound metabolites generated from toluene and o -xylene in soil, International Biodeterioration \& Biodegradation, 51(2), 129-132.

Wang X., Wang Q., Li S. and Wei L. (2015), Degradation pathway and kinetic analysis for $p$-xylene removal by a novel Pandoraea sp. strain WL1 and its application in a biotrickling filter, Journal of Hazardous Materials, 288, 17-24.

Yang Q., Shang H.T., Hui-Di L.I., Hong-Bo X.I. and Wang J.L. (2008), Biodegradation of Tetrachlorothylene Using Methanol as Cometabolic Substrate 1, Biomedical and Environmental Sciences, 21(2), 98-102.

Yao Y., Lv Z., Min H., Lv Z. and Jiao H. (2009), Isolation, identification and characterization of a novel Rhodococcus sp. strain in biodegradation of tetrahydrofuran and its medium optimization using sequential statistics-based experimental designs, Bioresource Technology, 100(100), 2762-2769.

Zeinali M., Vossoughi M. and Ardestani S.K. (2008), Naphthalene metabolism in Nocardia otitidiscaviarum strain TSH1, a moderately thermophilic microorganism, Chemosphere, 72(6), 905-909.

Zhang L., Zhang C., Cheng Z., Yao Y. and Chen J. (2012), Biodegradation of benzene, toluene, ethylbenzene, and o xylene by the bacterium Mycobacterium cosmeticum byf- 4 . Chemosphere, 90(4), 1340-1347. 